\title{
Results of palliation with an initial pulmonary artery band in patients with single ventricle associated with unrestricted pulmonary blood flow
}

\author{
Bahaaldin Alsoufi, MD, ${ }^{\mathrm{a}}$ Cedric Manlhiot, BSc, ${ }^{\mathrm{b}}$ Alexandra Ehrlich, ${ }^{\mathrm{c}}$ Matthew Oster, MD, ${ }^{\mathrm{c}}$ \\ Brian Kogon, MD, ${ }^{\mathrm{a}}$ William T. Mahle, MD, ${ }^{\mathrm{c}}$ Kevin Maher, MD, ${ }^{\mathrm{c}}$ Brian W. McCrindle, MD, MPH, ${ }^{\mathrm{b}}$ and \\ Kirk Kanter, MD
}

\begin{abstract}
Objectives: Pulmonary artery banding is the initial palliative surgery in patients with single ventricle cardiac anomalies presenting with unrestricted pulmonary blood flow. Reported mortality in those receiving pulmonary artery banding is high, and its application in patients with single ventricle anomalies and arch obstruction is controversial. We report current-era results after pulmonary artery banding in patients with single ventricle anomalies, including those with arch obstruction.
\end{abstract}

Methods: Between 2002 and 2012, 73 patients with single ventricle anomalies and unrestricted pulmonary blood flow underwent pulmonary artery banding, including 29 (40\%) who received simultaneous arch repair. Competing risk analysis modeled events after pulmonary artery banding (death/transplantation, transition to the Glenn procedure) and subsequently after the Glenn procedure (death/transplantation, transition to the Fontan procedure) and examined risk factors affecting outcomes.

Results: Hospital mortality was 3 of 73 patients $(4 \%)$. Before the Glenn procedure, 16 patients (22\%) underwent 18 reoperations, including shunt $(\mathrm{n}=7)$, Damus-Kaye-Stansel connection plus shunt $(\mathrm{n}=5)$, pulmonary artery banding adjustment $(\mathrm{n}=5)$, and transplantation $(\mathrm{n}=1)$. On competing risk analysis, 2 years after pulmonary artery banding, $8 \%$ of patients have died or received transplantation, $88 \%$ have undergone the Glenn procedure, and 7\% were alive without the Glenn procedure. Five years after the Glenn procedure, $9 \%$ have died, $71 \%$ have undergone the Fontan procedure, and 20\% were alive awaiting the Fontan procedure. Overall survival 5 years after pulmonary artery banding was $86 \%$. On multivariable analysis, risk factors for mortality were associated genetic/extracardiac anomalies (hazard ratio, 3.7; 95\% confidence interval, $1.1-12.2 ; P=.03$ ) and high-risk morphology (heterotaxy, unbalanced atrioventricular septal defect, and mitral atresia) (hazard ratio, $4.1 ; 95 \%$ confidence interval, $1.1-15.6 ; P=.04$ ).

Conclusions: Pulmonary artery banding is an acceptable initial palliative strategy of selected patients with single ventricle cardiac anomalies and unrestricted pulmonary blood flow, including those with concomitant arch obstruction. Short- and long-term outcomes are generally good, although results diverge with the worst outcomes noted in patients with heterotaxy, unbalanced atrioventricular septal defect, or associated extracardiac anomalies. (J Thorac Cardiovasc Surg 2015;149:213-20)

See related commentary on pages $220-1$.

From the Division of Cardiothoracic Surgery, ${ }^{a}$ Children's Healthcare of Atlanta, Emory University School of Medicine, Atlanta, Ga; Labatt Family Heart Center, ${ }^{\text {b }}$ Hospital for Sick Children, University of Toronto, Toronto, Ontario, Canada; and Sibley Heart Center, ${ }^{\mathrm{c}}$ Children's Healthcare of Atlanta, Emory University School of Medicine, Atlanta, Ga.

Disclosures: Kevin Maher reports equity ownership in Sensiotec. All other authors have nothing to disclose with regard to commercial support.

Read at the 40th Annual Meeting of The Western Thoracic Surgical Association, Dana Point, California, June 25-28, 2014.

Received for publication June 24, 2014; revisions received July 30, 2014; accepted for publication Aug 1, 2014; available ahead of print Sept 1, 2014.

Address for reprints: Bahaaldin Alsoufi, MD, Division of Cardiothoracic Surgery, Emory University School of Medicine, Children's Healthcare of Atlanta, 1405 Clifton Rd, NE, Atlanta, GA 30322 (E-mail: balsoufi@ hotmail.com). $0022-5223 / \$ 36.00$

Copyright $\odot 2015$ by The American Association for Thoracic Surgery http://dx.doi.org/10.1016/j.jtcvs.2014.08.007
Multistage palliation is the mainstay in the management of infants born with single ventricle (SV) cardiac anomalies. The principles of first-stage palliation of patients with SV cardiac anomalies are consistent and aim to achieve unobstructed systemic cardiac output, unobstructed and controlled source of pulmonary blood flow, and unobstructed pulmonary venous return to the heart. ${ }^{1,2}$ The choice of initial palliative surgery depends on the specific anatomy and the degree of systemic/pulmonary outflow obstruction.

In patients with SV anomalies and unrestricted pulmonary blood flow (UPBF), initial palliation typically has been pulmonary artery banding (PAB). ${ }^{1-6}$ Nonetheless, several centers reported disappointing short- and long-term outcomes of patients with SV anomalies typically palliated with PAB, and some authors recommended the use of an aortopulmonary shunt plus division of the main pulmonary artery as an 


$$
\begin{aligned}
& \text { Abbreviations and Acronyms } \\
& \text { BTS }=\text { Blalock-Taussig shunt } \\
& \text { CI }=\text { confidence interval } \\
& \text { DKS }=\text { Damus-Kaye-Stansel } \\
& \text { ECMO }=\text { extracorporeal membrane oxygenation } \\
& \text { HR }=\text { hazard ratio } \\
& \text { IQR }=\text { interquartile range } \\
& \text { PAB }=\text { pulmonary artery banding } \\
& \text { SV }=\text { single ventricle } \\
& \text { SVOTO }=\text { systemic ventricular outflow tract } \\
& \text { obstruction } \\
& \text { TAPVC }= \text { total anomalous pulmonary venous } \\
& \text { connection } \\
& \text { UPBF }= \text { unrestricted pulmonary blood flow }
\end{aligned}
$$

alternative first-stage palliation strategy that would provide a more reliable source of pulmonary blood flow and more predictable pulmonary vascular protection. ${ }^{4-7}$

Infants with concomitant arch obstruction are especially challenging because they are at an increased risk for development of systemic ventricular outflow tract obstruction (SVOTO). ${ }^{1-4,7-10}$ The ventricular hypertrophy as a result of PAB can cause subsequent enlargement of a subaortic conus or reduction in the size of the bulboventricular foramen, both leading to the development of subaortic obstruction. ${ }^{1-4,7-10}$ SVOTO can create unfavorable hemodynamic conditions that can have detrimental effects on the future of patients with SV physiology, with failure to progress through palliative stages or late malfunction after final palliation. ${ }^{1-4,7-10}$ Therefore, the initial management strategy of patients with SV anomalies with UPBF and arch obstruction remains controversial, with many groups favoring an initial Norwood-type palliation rather than PAB and concomitant arch repair. ${ }^{1-3,7,9-12}$

Given the potential disadvantages of all the different alternative treatment strategies, we aim to report our recent institutional experience with the palliation of patients with SV physiology who have UPBF with initial $\mathrm{PAB}$, including those with simultaneous arch obstruction requiring repair, and to examine the risk factors that affect early and late survival in this challenging group of patients.

\section{PATIENTS AND METHODS \\ Inclusion Criteria}

Between 2002 and 2012, 73 infants with various SV anomalies associated with UPBF underwent PAB at Children's Healthcare of Atlanta, Emory University. PAB was the initial palliation in all 73 patients; none of them had a prior cardiac surgery. Patients who underwent bilateral branch PAB for hypoplastic left heart syndrome and associated anomalies were not included. Patients were identified using our institutional surgical database.
Demographic, anatomic, clinical, operative, and hospital details were abstracted from the medical records for analysis. Approval of this study was obtained from the Children's Healthcare of Atlanta Institutional Review Board, and requirement for individual consent was waived for this observational study.

\section{Follow-up}

Time-related outcomes were determined from recent office visits present on the electronic chart of Children's Healthcare of Atlanta system or from direct correspondence with other pediatric cardiologists outside of the system. Mean follow-up duration after PAB was $6.0 \pm 3.6$ years and was $93 \%$ complete.

\section{Statistical Analysis}

Data are presented as means with standard deviation, medians with interquartile ranges (IQRs), or frequencies as appropriate. Time-dependent outcomes (death/transplantation and survival to the Glenn procedure) after PAB and time-dependent outcomes (death/transplantation and survival to the Fontan procedure) after the Glenn procedure were parametrically modeled. Parametric probability estimates for time-dependent outcomes uses models based on multiple, overlapping phases of risk (available for use with the SAS system at http://www.clevelandclinic.org/heartcenter/ hazard). The HAZARD procedure uses maximum likelihood estimates to resolve risk distribution of time to event in up to 3 phases of risk (early, constant, and late). Competing risk analysis was performed to model the probability over time of each of 2 mutually exclusive end points after PAB: death/transplantation and survival to the Glenn; the remaining patients begin alive without the Glenn. After the Glenn procedure, mutually exclusive end points were death/transplantation and survival to the Fontan procedure, the remaining patients being alive awaiting the Fontan. Variables potentially influencing the likelihood of outcomes in the competing risk models were sought from demographic, anatomic, and surgical variables. Multivariable models were created using forward entry of variables given the limited sample size available for analysis. Effects of covariates on the probability of outcomes in competing risk models are given as hazard ratio (HR) with $95 \%$ confidence interval (CI). Clinical relevance of covariates of interest on the likelihood of selected outcomes was established by solving the regression equations for multiple "typical" test patients. All statistical analyses were performed using SAS version 9.3 (SAS Institute Inc, Cary, NC).

\section{RESULTS \\ Patients' Characteristics}

During the study period, 73 infants with SV anomalies associated with UPBF underwent PAB. There were 39 male infants $(53 \%)$. The median age at the time of PAB was 14 days (IQR, 6-43), and the median weight was 3.4 $\mathrm{kg}$ (IQR, 3.0-3.9), with 9 patients (12\%) weighing $2.5 \mathrm{~kg}$ or less. Eight children $(11 \%)$ were born prematurely at 36 weeks or less gestation, and 9 children $(12 \%)$ had associated genetic or major extracardiac anomalies. The specific morphology for the SV anomalies included tricuspid atresia $(n=14,19 \%)$, double outlet right ventricle $(\mathrm{n}=14,19 \%)$, heterotaxy syndrome $(\mathrm{n}=12,16 \%)$, double inlet left ventricle $(\mathrm{n}=11,15 \%)$, unbalanced atrioventricular septal defect $(\mathrm{n}=8,11 \%)$, mitral atresia $(\mathrm{n}=8,11 \%)$, and other $(n=6,8 \%)$. The predominant ventricle was of left morphology in 33 patients $(45 \%)$ and right morphology in 32 patients $(44 \%)$, and 8 patients (11\%) had 2 equally developed ventricles. 


\section{Operative Details}

PAB was performed as an isolated procedure in 34 patients $(47 \%)$, whereas the remaining 39 patients $(53 \%)$ received concomitant procedures, including aortic coarctation \pm arch hypoplasia repair $(\mathrm{n}=29,40 \%)$, atrial septectomy $(\mathrm{n}=8,11 \%)$, total anomalous pulmonary venous connection (TAPVC) repair $(\mathrm{n}=3,4 \%)$, and pacemaker implantation $(\mathrm{n}=1,1 \%)$. Cardiopulmonary bypass was used for concomitant cardiac surgery in 13 patients $(18 \%)$ ). Among the 29 patients who required arch repair, this was performed via left thoracotomy in 24 and midline sternotomy in 5 (including 2 patients with interrupted aortic arch). The ductus arteriosus was always ligated before PAB. An umbilical caval tape was used as a PAB. Trusler's formula was used for initial assessment of the diameter of the tape; however, this was often further adjusted with the aim to have a distal pulmonary artery pressure that was less than half-systemic and systemic oxygen saturation that was approximately $80 \%$ on $21 \%$ fraction of inspired oxygen. After adequate tightening, the tape was secured to the adventitia of the main pulmonary artery with fine polypropylene sutures to prevent its migration.

\section{Hospital Outcomes After Pulmonary Artery Banding}

After PAB, 3 patients $(4.1 \%)$ required extracorporeal membrane oxygenation (ECMO) support. Two patients received rescue ECMO for refractory postoperative cardiac arrest, and 1 patient received ECMO in the operating room after unplanned cardiac reoperation during the same admission.

Three patients $(4.1 \%)$ required early unplanned reoperations: Severe low cardiac output after arch repair and PAB developed in 1 patient with unbalanced atrioventricular septal defect, who required an early conversion to a Damus-Kaye-Stansel (DKS) connection plus a modified Blalock-Taussig shunt (BTS) the following day; 1 patient with heterotaxy syndrome had persistent myocardial dysfunction after $\mathrm{PAB}$ and pacemaker implantation, who received heart transplantation 29 days after $\mathrm{PAB}$; and cyanosis developed after surgery in 1 patient with heterotaxy syndrome, who underwent $\mathrm{PAB}$ and obstructed TAPVC repair, requiring the addition of a BTS. The first 2 patients survived, but the latter patient did not.

Hospital mortality occurred in 3 patients $(4.1 \%)$. All of these deaths were in patients with heterotaxy syndrome, and 2 of them required concomitant obstructed TAPVC repair.

\section{Competing Risks Analysis After Pulmonary Artery Banding}

After the 73 initial PAB surgeries, 16 patients (22\%) underwent cardiac reoperation before the Glenn operation. Of those, 3 patients underwent reoperation during the same initial admission as discussed earlier, whereas the remaining 13 patients had 15 interim reoperations after hospital discharge, including a BTS for progressive cyanosis $(\mathrm{n}=6)$, DKS plus BTS for early development of SVOTO $(\mathrm{n}=4$, performed at 59,72, 87, and 96 days after PAB), PAB loosening $(n=2)$, PAB tightening $(n=2)$, and PAB revision for erosion into the main pulmonary artery $(\mathrm{n}=1)$.

After the initial 73 PAB surgeries, 65 patients $(89 \%)$ underwent the Glenn operation, 6 patients $(8 \%)$ died before the Glenn procedure ( 3 interstage mortalities in addition to the 3 hospital deaths listed earlier), 1 patient ( $1 \%$ ) received heart transplantation, and 1 patient $(1 \%)$ remains in a balanced physiology and has not undergone the Glenn yet. The 3 interstage mortalities included 1 patient with Down syndrome and unbalanced atrioventricular septal defect, who was not thought to be a good candidate for the Glenn operation because of multiple cardiac and extracardiac morbidities, including severe atrioventricular valve regurgitation, seizures, and bilateral hydronephrosis; 1 patient with double outlet right ventricle, who had necrotizing enterocolitis and neurologic insult before arch repair and $\mathrm{PAB}$ and died at home after a prolonged hospital stay; and 1 patient with unbalanced atrioventricular septal defect, who had arch repair and PAB and was readmitted with severe ventricular dysfunction, recurrent arch obstruction, and pulmonary artery stenosis and died after a prolonged hospital stay after cardiac reoperation.

Of the 65 patients undergoing the Glenn operation, 14 $(22 \%)$ had bilateral SVC, and therefore a bilateral bidirectional Glenn connection was performed. A total of 35 patients (54\%) underwent concomitant surgeries during the Glenn operation. These included atrial septectomy $(\mathrm{n}=18,28 \%)$, DKS connection $(\mathrm{n}=22,34 \%)$, pulmonary artery augmentation $(\mathrm{n}=16,25 \%)$, repair of residual arch obstruction ( $\mathrm{n}=2,3 \%)$, repair of partial anomalous pulmonary venous connection $(\mathrm{n}=2,3 \%)$, and placement of a permanent pacemaker $(\mathrm{n}=2,3 \%)$. Of note, 5 patients $(8 \%)$ had an interrupted inferior vena cava and naturally underwent the Kawashima operation at the time of the Glenn procedure.

Competing risk model showed that the proportion of patients who underwent the Glenn operation started to increase at approximately 4 months and peaked at approximately 6 months after PAB. The hazard function for death before the Glenn procedure was characterized by the presence of an early hazard phase during the initial 3 months after PAB but disappeared after that period. Competing risk analysis showed that at 6 months after $\mathrm{PAB}, 8 \%$ of patients had died or received transplantation, $50 \%$ had undergone the Glenn, and $42 \%$ were alive awaiting the Glenn. At 2 years after PAB, $8 \%$ of patients had died or received transplantation, $88 \%$ had undergone the Glenn, and $7 \%$ were alive awaiting the Glenn (Figure 1). 




FIGURE 1. Competing risk depiction of events after PAB. Analysis showed that at 6 months after PAB, $8 \%$ of patients had died or received transplantation, $50 \%$ had undergone the Glenn, and $42 \%$ were alive awaiting the Glenn. At 2 years after PAB, $8 \%$ of patients had died or received transplantation, $88 \%$ had undergone the Glenn, and $7 \%$ were alive awaiting the Glenn. $P A B$, Pulmonary artery banding.

\section{Competing Risks Analysis After the Glenn Procedure}

After the 65 Glenn procedures, 37 patients (57\%) underwent the Fontan operation, 4 patients $(6 \%)$ died before the Fontan, and 24 patients $(37 \%)$ were alive awaiting Fontan surgery (including $4 / 5$ patients who underwent the Kawashima operation, whereas the fifth patient who underwent the Kawashima operation underwent Fontan completion).

The 4 deaths after the Glenn procedure before the Fontan procedure included 1 patient with unbalanced atrioventricular septal defect, who had extensive thrombosis of the superior vena cava and pulmonary arteries with cardiac arrest after the Glenn and DKS and required pulmonary embolectomy and takedown of the Glenn but did not survive

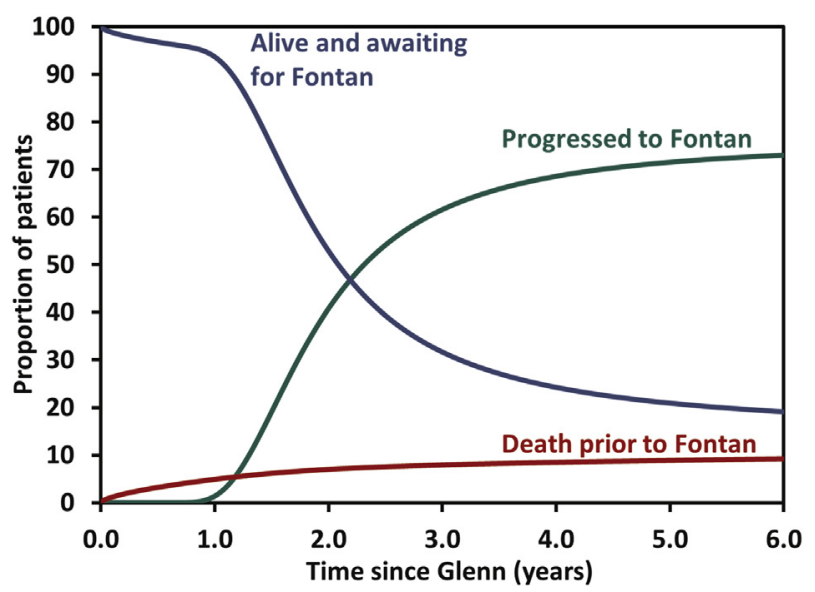

FIGURE 2. Competing risk depiction of events after the Glenn procedure. Analysis showed that at 2 years after the Glenn, 7\% of patients had died, $41 \%$ had undergone the Fontan, and 52\% were alive awaiting the Fontan. At 5 years after the Glenn, $9 \%$ of patients had died, $71 \%$ had undergone Fontan, and 20\% were alive awaiting the Fontan. hospitalization; 1 patient with mitral atresia, who died of abdominal complications after readmission for Nissen fundoplication; 1 patient with double inlet left ventricle, who died of sickle cell disease complicated by multiple cerebrovascular accidents; and 1 patient with unbalanced atrioventricular septal defect, who died at home after multiple recent emergency department visits and admissions for diarrhea, dehydration, and metabolic acidosis.

Competing risk model showed that the proportion of patients who underwent the Fontan procedure started to increase at approximately 1 year and peaked at approximately 1.7 years after the Glenn procedure. The hazard function for death before the Fontan was characterized by the presence of an early hazard phase during the initial 3 months after surgery and a persistent low hazard of death that continued with constant attrition for approximately 3 years after the Glenn procedure.

Competing risk analysis showed that at 2 years after the Glenn procedure, $7 \%$ of patients had died, $41 \%$ of patients had undergone the Fontan operation, and $52 \%$ of patients were alive awaiting the Fontan operation. At 5 years after the Glenn procedure, $9 \%$ of patients had died, $71 \%$ had undergone the Fontan, and 20\% were alive awaiting the Fontan (Figure 2).

\section{Overall Survival and Risk Factors}

Overall survival for the entire cohort after initial PAB surgery was $97 \%$ at 1 month, $90 \%$ at 1 year, and $86 \%$ at 5 years. The hazard function for overall death after PAB was characterized by the presence of an early hazard phase during the initial 4 months after surgery and a persistent low hazard of death that continued 4 years after PAB with low but constant attrition as years went by (Figure 3, $A$ and $B$ ).

On multivariable analysis, risk factors for overall mortality were the presence of associated genetic or major extracardiac anomalies (HR, 3.7; 95\% CI, 1.1-12.2; $P=.03$ ) (Figure 4) and a higher risk morphology (combining heterotaxy, unbalanced atrioventricular septal defect, and mitral atresia cases) category (HR, 4.1; 95\% CI, 1.1-15.6; $P=.04$ ) (Figure 5). Of note, concomitant arch repair at the time of PAB was not found on univariate analysis to be associated with a significant decrease in overall survival (HR 2.2; 95\% CI, 0.7-7.1; $P=.17$ ) (Figure 6).

\section{DISCUSSION}

Patients with various SV anomalies associated with UPBF require early control with PAB to prevent pulmonary overcirculation and the later development of pulmonary vascular disease. The main advantages of this strategy are the avoidance of cardiopulmonary bypass in the neonatal period and a lower risk of thrombotic occlusion than might occur with a BTS. Nonetheless, there are several drawbacks to $\mathrm{PAB}$ related to the difficulty obtaining 



FIGURE 3. Time-dependent survival (A) and risk hazard of death (B) over time after PAB. The hazard function for death after PAB was characterized by the presence of an early hazard phase during the initial 4 months after surgery and a persistent low hazard of death that continued 4 years after PAB with low but constant attrition as years went by. The solid lines in the parametric model represent parametric point estimates, and the dashed lines enclose the $95 \% \mathrm{CI}$. Circles represent nonparametric estimates. $P A B$, Pulmonary artery banding.

adequate pulmonary vascular protection with $\mathrm{PAB}$, the possibility of pulmonary artery distortion or pulmonary valve damage with subsequent regurgitation, and, most important, the occurrence of ventricular hypertrophy that might accelerate the rate of bulboventricular foramen narrowing with subsequent early development of SVOTO. ${ }^{2,4-9}$ Our study demonstrates that the rate of reintervention after PAB before the Glenn procedure is high $(22 \%)$, with a number of patients demonstrating cyanosis requiring band loosening or more commonly the addition of a BTS, and an additional number of patients demonstrating a loose band with inadequate protection requiring band tightening. Despite reintervention, the mortality risk was low, and most of those patients made the expected progression toward the Glenn procedure without long-term consequences. These results seem to be superior compared with other studies showing a high mortality rate for the patients who required reintervention after PAB. ${ }^{13}$ Interim cardiac reinterventions are known to occur after various first-stage

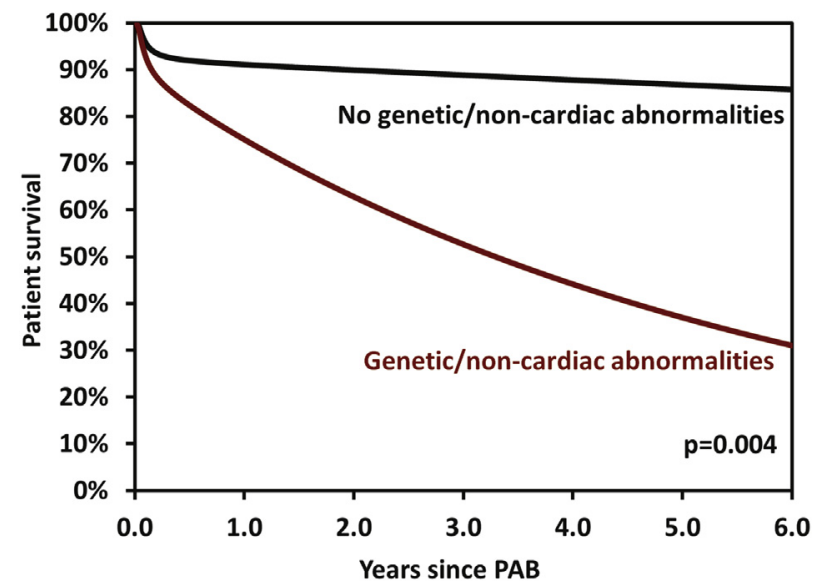

FIGURE 4. Parametric model for survival after PAB stratified by the presence or absence of associated genetic or major extracardiac anomalies. $P A B$, Pulmonary artery banding. surgeries in patients with $\mathrm{SV}$, and $\mathrm{PAB}$ is not an exception to this, although it seems that the current negative impact of PAB reintervention on late outcomes is less pronounced in this cohort than that after the Norwood or BTS. ${ }^{14,15}$

Reported hospital mortality after PAB continues to be high; in the latest Society of Thoracic Surgeons harvest, hospital mortality for PAB was $8.9 \%$. In our current series, hospital mortality was favorable at $4.1 \%$ and lower than that reported for other first-stage palliative procedures (ie, BTS and Norwood). ${ }^{16,17}$ All of our 3 hospital mortalities were in patients with heterotaxy syndrome, and 2 of them required concomitant obstructed TAPVC repair. Patients with heterotaxy syndrome continue to be a challenge; a recent Society of Thoracic Surgeons study examining the hospital survival of 1505 patients with heterotaxy who underwent surgery demonstrated that discharge mortality was higher in patients with heterotaxy compared with patients without heterotaxy for every procedure mortality risk category. ${ }^{18}$ The association of TAPVC in those with heterotaxy is especially complicated, and reported outcomes from various institutions continue to show a high mortality rate. ${ }^{19-21} \mathrm{PAB}$ during TAPVC repair in patients with heterotaxy is challenging because of the inability to accurately predict the amount of native pulmonary outflow obstruction, difficulty to adequately perform $\mathrm{PAB}$ in patients after obstructed TAPVC repair because of varying degrees of lung pathology, and elevated pulmonary vascular resistance. The high incidence of associated intracardiac anomalies, particularly atrioventricular valve regurgitation and conduction abnormalities, adds to the challenge. Whether alternative strategies, such as TAPVC repair plus shunt, provide a more controllable physiologic state remains to be determined. Our institutional outcomes and other reported results suggest that TAPVC and shunt are associated with a similar early and late mortality risk, indicating ongoing difficulty in the management of these complex cases. ${ }^{17-21}$ 


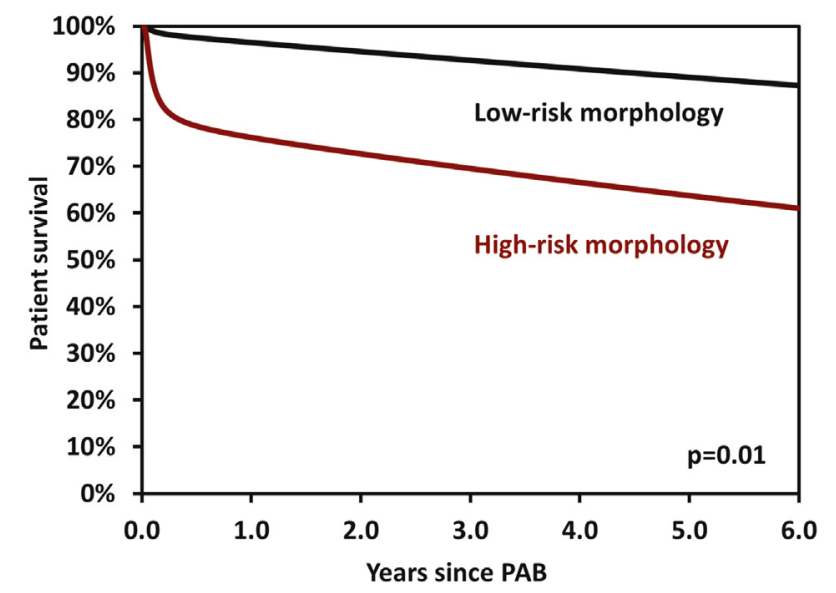

FIGURE 5. Parametric model for survival after $P A B$ stratified by the presence or absence of high-risk morphology (ie, heterotaxy, unbalanced atrioventricular septal defect, and mitral atresia). $P A B$, Pulmonary artery banding.

In addition to early mortality risk, historic late outcomes after PAB in patients with SV anomalies have been disappointing. ${ }^{2,4-9}$ Franklin and colleagues ${ }^{5}$ found that survival after $\mathrm{PAB}$ was $77 \%$ at 1 year and $45 \%$ at 5 years for those who had PAB alone and $44 \%$ at 1 year and $22 \%$ at 5 years for those who had PAB and aortic arch repair. ${ }^{5}$ In another study by Franklin and colleagues, ${ }^{6}$ the suitability for the Fontan operation was $42 \%$ for those who had PAB alone and $8 \%$ for those who had PAB and aortic arch repair. Our current results are encouraging, and the risk of interim mortality or failure to progress through subsequent palliative stages is low, especially taking into consideration that the majority of patients in those older studies had tricuspid atresia or double inlet left ventricle, both being favorable morphologies associated with higher long-term survival in our current series. Those superior contemporary results are credited to improvements in perioperative care, patient

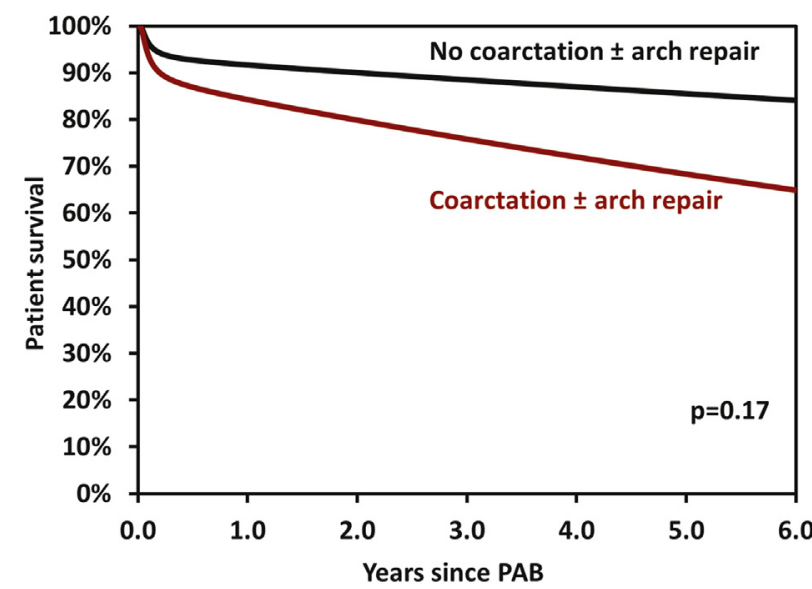

FIGURE 6. Parametric model for survival after $P A B$ stratified by performance of concomitant aortic coarctation/arch repair at the time of PAB versus no repair. $P A B$, Pulmonary artery banding. selection, postoperative monitoring, and management; in addition, the Glenn operation is typically performed at 4 to 6 months of age in the current palliation strategies as opposed to prolonged PAB application in older series. ${ }^{2,4-6}$

In recognition of the potential complications associated with PAB in patients with SV, Bradley and colleagues ${ }^{7}$ adopted a palliative strategy for patients with SV with UPBF by dividing the main pulmonary artery and placing a BTS (with DKS in patients at risk of developing SVOTO) as an alternative strategy to PAB. They hypothesized that this strategy would provide a more reliable source of pulmonary blood flow and a more predictable pulmonary vascular protection. They reported excellent early and late outcomes with no operative mortality and 1 late death, with all survivors receiving a subsequent Glenn procedure. We have not adopted such a strategy at our institution given the low operative mortality risk and low interim mortality after PAB, especially in patients without heterotaxy syndrome. Moreover, our early and interim mortality after PAB remain lower than after a BTS or Norwood reported from our hospital or other institutions and registries. ${ }^{14-17}$

Most important, the risk of developing SVOTO after PAB is the most recognized PAB complication that can result in unexpected mortality, failure to progress toward subsequent palliative surgeries, or late failure after final palliation. This risk was found to be higher in patients with a small bulboventricular foramen and was especially high in patients with concomitant arch obstruction. ${ }^{2,4-10}$ Some $40 \%$ of the patients in our series had concomitant arch obstruction and therefore were at a higher risk of SVOTO developing. Although some surgeons continue to perform PAB and concomitant arch repair in selected patients with SV with UPBF at risk of subsequent SVOTO development, many others have recommended that SVOTO be addressed at the time of the first-stage procedure with DKS plus shunt or a Norwood-type first-stage palliation if concomitant arch reconstruction is needed. ${ }^{1-3,7,9-13,22-25}$ Theoretic advantages of the latter approach include the ability to address SVOTO early on and concomitantly address all types of arch pathology, prevention of development of ventricular hypertrophy and subsequent diastolic dysfunction, avoidance of pulmonary valve distortion and subsequent regurgitation or pulmonary artery branch stenosis, and having a uniform shunt diameter with more predictable pulmonary blood flow compared with PAB. ${ }^{2,9-13}$ The obvious disadvantages of that strategy include cardiopulmonary bypass and deep hypothermic circulatory arrest need during the neonatal period, complex postoperative course, shunt-related complications, and early and interim mortality risk. ${ }^{2,9,14,16}$ Serraf and colleagues ${ }^{10}$ compared outcomes in patients with SV anomalies who have undergone various initial palliations and found that 4-year survival was better in those who had undergone the 
DKS or palliative arterial switch operation than those who had undergone $\mathrm{PAB}$ and aortic arch repair $(67 \%$ vs $40 \%$, $P<.05) .{ }^{10}$ Lee and colleagues ${ }^{3}$ followed the outcomes of 70 infants with SV, UPBF, and arch obstruction (excluding hypoplastic left heart syndrome) and found that the overall survival was $53 \%$ at 10 years and comparable between patients who received an initial $\mathrm{PAB}$ and patients who received an initial DKS or $\operatorname{Norwood}(P=.3)$. Our retrospective study is not designed to identify the better approach for infants with SV anomalies, UPBF, and arch obstruction, and clearly there are infants with comparable intracardiac anomalies who have undergone a modified Norwood operation during the same study period. At our institution, patients with small aortic annulus, subaortic obstruction, small ascending aorta diameter, and proximal arch obstruction are more likely to undergo a Norwood operation, whereas the occasional patients with SV anomalies with coarctation/distal arch hypoplasia without significant subaortic obstruction are considered for arch repair plus $\mathrm{PAB}$. The current results in our patients who have undergone $\mathrm{PAB}$ and arch repair are encouraging, suggesting that this strategy is recommended in selected groups of patients. Five patients in our series underwent an interim DKS and BTS before the Glenn procedure; 1 was required 1 day after PAB because of severe SVOTO and low cardiac output, and that was clearly a patient in whom PAB was not the correct choice. The other 4 patients demonstrated evidence of SVOTO 2 to 3 months after PAB, and the decision was made to perform the DKS and BTS rather than the DKS and Glenn because of clinical and age considerations. Arguably, some of those patients could have received an early Glenn plus DKS; nonetheless, 4 of 5 of those patients survived to progress to a subsequent Glenn operation. These findings underscore the importance of vigilant follow-up in the management of those patients. At our institution, all infants with SV are followed closely after their first-stage palliation surgery (shunt, PAB, or Norwood) through the complex congenital heart disease program until the time of their second-stage of palliation. We have a low threshold for hospital readmission in those patients with any sign of illness, such as poor weight gain, fever, diarrhea, vomiting, hypoxia, and respiratory distress. High-risk patients identified at the time of discharge, including those at risk for development of SVOTO, are followed more strictly at closer intervals with more frequent imaging and phone checkups.

Ultimately, 27 patients received the DKS after PAB. Although several groups have raised concerns about the development of pulmonary regurgitation in patients who undergo the DKS after PAB, this issue does not seem to be a problem, and several reports have demonstrated that a prior $\mathrm{PAB}$ did not increase the risk of neoaortic valve regurgitation after succeeding the DKS. $1,2,13,22-25$

\section{CONCLUSIONS}

The outcomes of PAB for the palliation of patients with SV anomalies with UPBF are good, including patients with simultaneous arch obstruction. Reoperation is common for pulmonary or systemic outflow obstruction, underscoring the importance of vigilant monitoring after hospital discharge. Genetic/extracardiac anomalies and high-risk pathologies such as heterotaxy syndrome and unbalanced atrioventricular septal defect decrease survival, indicating an ongoing opportunity to improve outcomes in these complicated cases.

\section{References}

1. Rodefeld MD, Ruzmetov M, Schamberger MS, Girod DA, Turrentine MW, Brown JW. Staged surgical repair of functional single ventricle in infants with unobstructed pulmonary blood flow. Eur J Cardiothorac Surg. 2005;27:949-55.

2. Alsoufi B. Management of the single ventricle and potentially obstructive systemic ventricular outflow tract. J Saudi Heart Assoc. 2013;25:191-202.

3. Lee MG, Brizard CP, Galati JC, Iyengar AJ, Rakhra SS, Konstantinov IE, et al Outcomes of patients born with single-ventricle physiology and aortic arch obstruction: the 26-year Melbourne experience. J Thorac Cardiovasc Surg. 2014; 148:194-201

4. Freedom RM, Benson LN, Smallhorn JF, Williams WG, Trusler GA, Rowe RD. Subaortic stenosis, the univentricular heart, and banding of the pulmonary artery: an analysis of the courses of 43 patients with univentricular heart palliated by pulmonary artery banding. Circulation. 1986;73:758-64.

5. Franklin RC, Spiegelhalter DJ, Anderson RH, Macartney FJ, Rossi Filho RI, Rigby ML, et al. Double-inlet ventricle presenting in infancy II. Results of palliative intervention. J Thorac Cardiovasc Surg. 1991;101:917-23.

6. Franklin RC, Spiegelhalter DJ, Rossi Filho RI, Macartney FJ, Anderson RH, Rigby ML, et al. Double-inlet ventricle presenting in infancy III. Outcome and potential for definitive repair. J Thorac Cardiovasc Surg. 1991;101:924-34.

7. Bradley SM, Simsic JM, Atz AM, Dorman BH. The infant with single ventricle and excessive pulmonary blood flow: results of a strategy of pulmonary artery division and shunt. Ann Thorac Surg. 2002;74:805-10.

8. Matitiau A, Geva T, Colan SD, Sluysmans T, Parness IA, Spevak PJ, et al Bulboventricular foramen size in infants with double-inlet left ventricle or tricuspid atresia with transposed great arteries: influence on initial palliative operation and rate of growth. J Am Coll Cardiol. 1992;19:142-8.

9. Fraser CD Jr. Management of systemic outlet obstruction in patients undergoing single ventricle palliation. Semin Thorac Cardiovasc Surg Pediatr Card Surg Апnи. 2009;70-5.

10. Serraf A, Conte S, Lacour-Gayet F, Bruniaux J, Sousa-Uva M, Roussin R, et al. Systemic obstruction in univentricular hearts: surgical options for neonates. Ann Thorac Surg. 1995;60:970-7.

11. Mosca RS, Hennein HA, Kulik TJ, Crowley DC, Michelfelder EC Ludomirsky A, et al. Modified Norwood operation for single left ventricle and ventriculoarterial discordance: an improved surgical technique. Ann Thorac Surg. 1997;64:1126-32.

12. Tchervenkov CI, Shum-Tim D, Béland MJ, Jutras L, Platt R. Single ventricle with systemic obstruction in early life: comparison of initial pulmonary artery banding versus the Norwood operation. Eur J Cardiothorac Surg. 2001;19:671-7.

13. Fiore AC, Rodefeld M, Vijay P, Turrentine M, Seithel C, Ruzmetov M, et al. Subaortic obstruction in univentricular heart: results using the double barrel DamusKaye Stansel operation. Eur J Cardiothorac Surg. 2009;35:141-6.

14. Newburger JW, Sleeper LA, Frommelt PC, Pearson GD, Mahle WT, Chen S et al. Transplantation-free survival and interventions at 3 years in the single ventricle reconstruction trial. Circulation. 2014;129:2013-20.

15. McKenzie ED, Khan MS, Samayoa AX, Vener DS, Ishak YM, Santos AB, et al The Blalock-Taussig shunt revisited: a contemporary experience. J Am Coll Surg. 2013;216:699-704.

16. Ohye RG, Schonbeck JV, Eghtesady P, Laussen PC, Pizarro C, Shrader P, et al Cause, timing, and location of death in the Single Ventricle Reconstruction trial. J Thorac Cardiovasc Surg. 2012;144:907-14.

17. Petrucci O, O’Brien SM, Jacobs ML, Jacobs JP, Manning PB, Eghtesady P. Risk factors for mortality and morbidity after the neonatal Blalock-Taussig shunt procedure. Ann Thorac Surg. 2011;92:642-51. 
18. Jacobs JP, Pasquali SK, Morales DL, Jacobs ML, Mavroudis C, Chai PJ, et al. Heterotaxy: lessons learned about patterns of practice and outcomes from the congenital heart surgery database of the society of thoracic surgeons. World J Pediatr Congenit Heart Surg. 2011;2:278-86.

19. Caldarone CA, Najm HK, Kadletz M, Smallhorn JF, Freedom RM, Williams WG, et al. Surgical management of total anomalous pulmonary venous drainage: impact of coexisting cardiac anomalies. Ann Thorac Surg. 1998;66:1521-6.

20. Hancock Friesen CL, Zurakowski D, Thiagarajan RR, Forbess JM, del Nido PJ, Mayer JE, et al. Total anomalous pulmonary venous connection: an analysis of current management strategies in a single institution. Ann Thorac Surg. 2005; 79:596-606.

21. Lodge AJ, Rychik J, Nicolson SC, Ittenbach RF, Spray TL, Gaynor JW. Improving outcomes in functional single ventricle and total anomalous pulmonary venous connection. Ann Thorac Surg. 2004;78:1688-95.
22. Daenen W, Eyskens B, Meyns B, Gewillig M. Neonatal pulmonary artery banding does not compromise the short-term function of a Damus-Kaye-Stansel connection. Eur J Cardiothorac Surg. 2000;17:655-7.

23. Odim JN, Laks H, Drinkwater DC Jr, George BL, Yun J, Salem M, et al. Staged surgical approach to neonates with aortic obstruction and single ventricle physiology. Ann Thorac Surg. 1999;68:962-8.

24. Clark AJB, Kasahara S, Andrews DR, Cooper SG, Nicholson IA, Chard RB, et al. Mid-term results for double inlet left ventricle and similar morphologies: timing of Damus Kaye Stansel. Ann Thorac Surg. 2004;78:650-7.

25. Alsoufi B, Al-Wadai A, Khan M, Al-Ahmadi M, Kalloghlian A, Bulbul Z, et al. Outcomes of Damus-Kaye-Stansel anastomosis at time of cavopulmonary connection in single ventricle patients at risk of developing systemic ventricular outflow tract obstruction. Eur J Cardiothorac Surg. 2014;45: $77-82$.

\title{
EDITORIAL COMMENTARY
}

\section{Strike up the band!}

\author{
Harold M. Burkhart, MD
}

See related article on pages 213-20.

Over the past 2 decades, there has been a trend to avoid main pulmonary artery banding and advocate for early definitive surgical repair or alternate palliative strategies. This controversy is nowhere more apparent than when discussing the management of patients with a single ventricle with unrestricted pulmonary blood flow, particularly those with the potential for developing systemic ventricular outflow tract obstruction. These patients typically present with a double inlet left ventricle with discordant ventriculoarterial connection, tricuspid atresia with discordant ventriculoarterial connection, and double outlet right ventricle with mitral atresia. The patients are at risk of developing outflow tract obstruction at the level of the bulboventricular foramen, which is the pathway into the rudimentary subaortic outlet chamber. Ventricular hypertrophy secondary to a pulmonary band may lead to subaortic obstruction resulting from an increasingly restrictive bulboventricular foramen, enlarging subaortic conus, or both. In addition, concerns exist regarding ventricular diastolic dysfunction due to hypertrophy. Other

From the Division of Cardiovascular and Thoracic Surgery, Children's Hospital of Oklahoma, University of Oklahoma Health Sciences Center, Oklahoma City, Okla. Disclosures: Author has nothing to disclose with regard to commercial support.

Received for publication Oct 5, 2014; accepted for publication Oct 6, 2014; available ahead of print Nov 4, 2014.

Address for reprints: Harold M. Burkhart, MD, Division of Cardiovascular and Thoracic Surgery, Children's Hospital of Oklahoma, University of Oklahoma Health Sciences Center, PO Box 26901, WP-2230, Oklahoma City, OK 73105 (E-mail: Harold-burkhart@ouhsc.edu).

J Thorac Cardiovasc Surg 2015;149:220-1

$0022-5223 / \$ 36.00$

Copyright (c) 2015 by The American Association for Thoracic Surgery

http://dx.doi.org/10.1016/j.jtcvs.2014.10.019 issues with pulmonary artery band placement in patients with a single ventricle include distortion of the branch pulmonary arteries or pulmonary valve as well as the adequacy of the band to provide appropriate pulmonary blood flow.

Alsoufi and colleagues ${ }^{1}$ present a timely, comprehensive 10-year review of their experience with pulmonary artery banding in 73 patients who presented with a single ventricle and unrestricted pulmonary blood flow. The patient group was a complex group, including heterotaxy and mitral atresia as well as double inlet left ventricle and tricuspid atresia; $40 \%$ required aortic arch/coarctation repair. Early mortality was excellent at $4.1 \%$. Reoperation before staged Glenn operation was required in $22 \%$ of patients. Only 4 of these reoperations were for the development of systemic ventricular outflow tract obstruction, and none were in patients with double inlet left ventricle. Despite this, the majority of patients $(89 \%)$ progressed to Glenn operation.

The authors ${ }^{1}$ make a strong case-one that I wholeheartedly agree with - for the use of pulmonary artery banding in patients with a single ventricle with unobstructed pulmonary blood flow. There are, of course, going to be times when a more definitive procedure will be required as in the case of a restrictive bulboventicular foramen or a significantly hypoplastic aortic valve, outflow tract, or ascending aorta. However, if given the option of a pulmonary artery band there are obvious advantages, including the avoidance of cardiopulmonary bypass and the ability to perform the operation with minimal insult. Care has to be taken to ensure the band is placed above the pulmonary valve and below the branch pulmonary arteries to avoid distortion. Band stay sutures placed strategically are necessary to avoid band migration. After 